\title{
Colecistitis aguda por Streptococcus constellatus
}

\author{
Acute cholecystitis by Streptococcus constellatus
}

\author{
M Sandra Gómez-Canosa1', Cristina Lijó-Carballeda², Begoña Vázquez-Vázquez², M José Bello-Peón ${ }^{3}$ \\ ${ }^{1}$ Servicio de Medicina Intensiva. ${ }^{2}$ Servicio de Medicina Interna. ${ }^{3}$ Servicio de Radiología. \\ Complexo Hospitalario Universitario de Ferrol (CHUF). SERGAS. Avenida da Residencia, s/n, Ferrol. 15405, A Coruña. España.
}

\begin{abstract}
Resumen
Presentamos el caso de una paciente de edad avanzada y significativa comorbilidad que se diagnosticó de colecistitis aguda por Streptococcus constellatus.

El drenaje de la vesícula biliar por colecistostomía percutánea, asociado a penicilinas, ha conseguido una evolución favorable.

Palabras clave: Streptococcus constellatus,

Colecistitis, Drenaje de vesícula biliar.
\end{abstract}

\section{Introducción}

La colecistitis aguda alcanza el 10\% de mortalidad en pacientes de alto riesgo. Por ello en pacientes de edad avanzada, diabéticos o inmunodeprimidos, la administración de antibiótico se hace rutinaria independientemente de la existencia de signos de sepsis. La colecistectomía precoz puede asociarse a menor morbimortalidad, pero se desaconseja en pacientes con alta mortalidad perioperatoria.

\section{Caso clínico}

Presentamos el caso de una mujer de 80 años, con vida basal limitada, obesa y con antecedentes de fibrilación auricular anticoagulada con warfarina e hipertensión arterial pulmonar severa en programa de oxigenoterapia domiciliaria. La paciente había sido intervenida de hernia abdominal incarcerada hace 2 años, siendo la cirugía abdominal complicada y necesitando reintervención precoz por dehiscencia de sutura (colocación de malla).

Es traída al Servicio de Urgencias por cuadro, de 7 días de evolución, de astenia, mareo y un único episodio de vómitos alimentarios. En la exploración física destacaba somnolencia y palidez cutánea (presión arterial 65/40mmHg). Temperatura de $38,3^{\circ} \mathrm{C}$. De las pruebas realizadas destacaban: analíticamente, leucocitosis de 15320/. $\mathrm{mm}^{3}$, procalcitonina de $23.53 \mathrm{ng} / \mathrm{mL}$ y bilirrubina total de $1.3 \mathrm{mg} / \mathrm{dL}$ y la ecografía abdominal visualizaba una vesícula biliar con evidencia de litiasis pero sin datos definitivos de colecistitis o ectasia de la vía biliar. Se decidió ingreso ingreso en UCl y se comenzó tratamiento empírico de amplio espectro con piperazilina-tazobactam. El urocultivo fue positivo para Escherichia coli (E coli) y en los hemocultivos creció un Streptococcus constellatus (S constellatus) sensible a penicilinas; se identifica ésta por sistema API-Strep (Biomèrieux), realizándose sensibilidad por el sistema disco placa, detectándose CMI por el sistema de microdilución en caldo sensitive (Thermo). La evolución fue inicialmente favorable trasladándose a planta a las 96 horas, donde, a pesar de tratamiento dirigido, se observó persistencia de fiebre y hemocultivos positivos, por lo que se realiza nueva ecografía abdominal ahora compatible con colecistitis aguda (figura 1), y posteriormente colecistostomía percutánea, por el Servicio de

\begin{abstract}
We report the case of a patient of advanced age and significant comorbidity diagnosed acute cholecystitis by Streptococcus constellatus.

Gallbladder drainage by percutaneous cholecystostomy associated with penicillins has achieved a favorable outcome.

Keywords: Streptococcus constellatus,

Cholecystitis, Gallbladder drainage.
\end{abstract}

Radiología, con catéter de 10F y abordaje anterior, extrayéndose material de aspecto purulento que se remite a microbiología. El cultivo del líquido biliar fue positivo para $E$ coliy $S$ constellatus sensible a penicilinas. Se cambia antibioterapia a amoxicilina-clavulánico. La paciente permaneció completamente afebril desde las $96 \mathrm{~h}$ post-colecistostomía, derivándose a domicilio con su drenaje biliar. A las 2 semanas se realiza una colangiografía a través del catéter de drenaje que objetiva ausencia de defectos de replección en la vía viliar y paso de contraste a duodeno normal (figura 2). Bajo recomendación del Servicio de Cirugía General se realiza pinzamiento diario progresivo del catéter, retirándose éste una semana después y tras un seguimiento de 8 meses la paciente se encuentra asintomática y en su situación basal.

\section{Discusión}

La colecistitis aguda es primariamente un proceso inflamatorio pero puede existir sobreinfección debido a obstrucción del conducto cístico y estasis biliar ${ }^{1}$. La mortalidad global de un episodio único de colecistitis aguda es aproximadamente del $3 \%$, aunque el riesgo individual depende del estado de salud previo y del riesgo inherente al proceso quirúrgico, siendo ésta inferior a un 1\% en pacientes jóvenes previamente sanos y hasta un $10 \%$ en pacientes de alto riesgo o con complicaciones. La existencia de sepsis o hallazgos radiológicos de isquemia o necrosis de la vesícula biliar sugiere la administración de antibióticos. También en pacientes mayores o con diabetes o inmunodeprimidos, aún sin signos de sepsis². Los principales microorganismos implicados son: Escherichia coli (41\%), Enterococcus (12\%), Klebsiella (11\%), Enterobacter (9\%).

En nuestro caso, se aislaron E coli y $S$ constellatus; este último forma parte del grupo milleri, estreptococo no hemolítico, comensal habitual de la cavidad oral, tracto grastointestinal y vagina. No suelen provocar infecciones. Sin embargo, están relacionados con el desarrollo de bacteriemia y forma- 
ción de abscesos (dentales, cerebrales, cavidad abdominal, endocarditis, empiema, epidural) en el seno de infecciones agudas de otro foco (coinfección), cirugías, manipulaciones de vía digestiva/aérea o enfermedad subyacente moderada-severa ${ }^{3}$. Cuando no existe absceso clínicamente aparente, el aislamiento de dicho microorganismo exige evaluación exhaustiva en su búsqueda. La presencia de hemocultivos positivos deberían guiar a detectar infección abdominal oculta, infección supurativa focal 0 a distancia ${ }^{4}$. La presencia de

Figura 1. Vesícula distendida con presencia de abundante barro con formación de un nivel y múltiples cálculos.

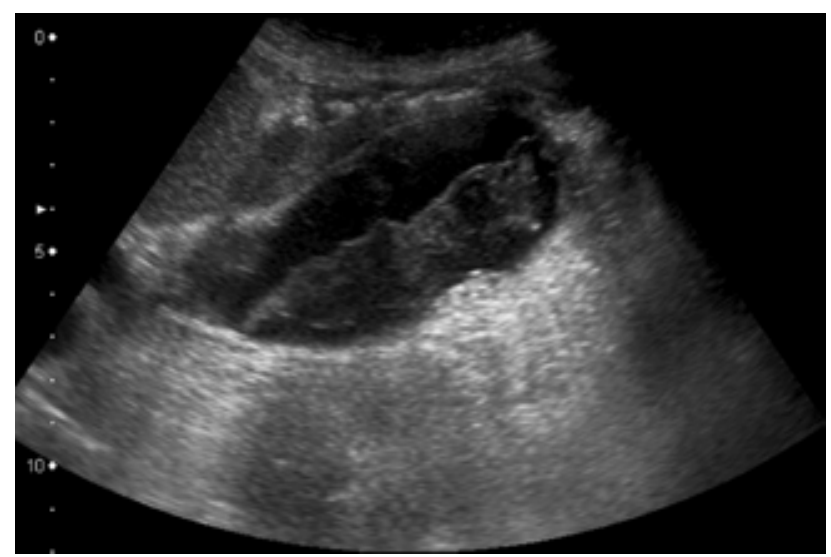

Figura 2. Ausencia de defectos de replección en la vía biliar con paso de contraste a duodeno normal.

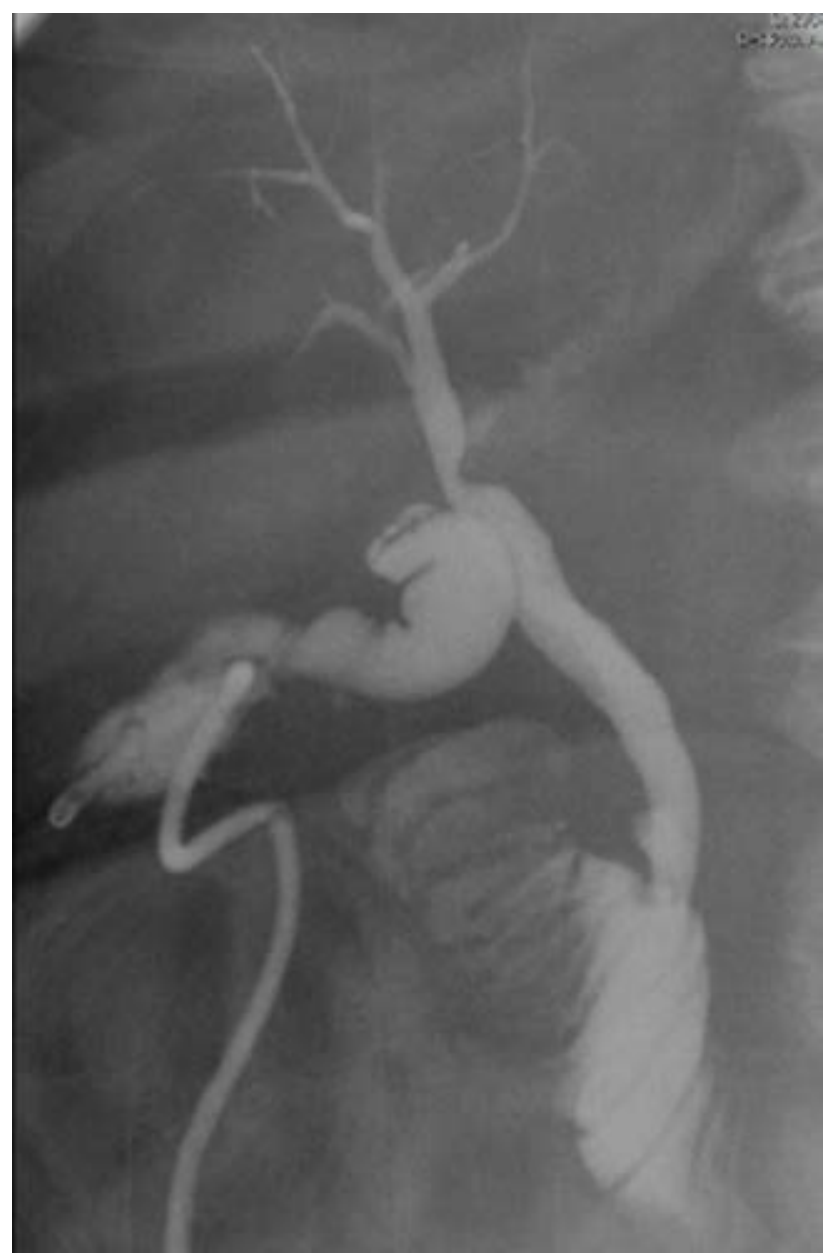

otros microorganismos como E coli y Bacteroides fragillis es común, actuando de forma sinérgica mediante la inhibición de la fagocitosis de las bacterias aerobias, alterando el entorno local y produciendo sustancias tóxicas que suprimen la actividad bactericida de las células defensivas del huésped ${ }^{5}$. El uso racional de antibióticos se basa en el resultado de cultivos biliares. El tratamiento fundamental de las infecciones por $S$ constellatus sigue siendo la penicilina o las cefalosporinas de $3^{\mathrm{a}}$ generación, asociando fármacos con actividad anaerobicida si existe coinfección por anaerobios.

Nuestra paciente era una pobre candidata a cirugía, por lo que, y tras consensuar con los Servicios de Radiología y Cirugía General, se realizó colecistostomía percutánea bajo anestesia local con guía ecográfica. El drenaje de vesícula biliar busca eliminar el material purulento que causa obstrucción del conducto cístico, permitiendo la resolución del edema. Puede realizarse vía quirúrgica o endoscópica ${ }^{6}$. Junto con la asociación de antibióticos puede ser el mejor tratamiento para pacientes muy enfermos ${ }^{7}$. La colecistostomía percutánea es una técnica de gran éxito (82-100\%) y con un bajo número de complicaciones, que habitualmente resuelve la colecistitis aguda ${ }^{8}$. Aunque en nuestra paciente no se consideró el mantenimiento indefinido del catéter, queda aún por precisar la actitud óptima a seguir en pacientes con colecistitis aguda litiásica descartados definitivamente para cirugía diferida, pues es en éstos donde se describe un elevado riesgo de recurrencia ${ }^{8,9}$.

En conclusión, el $S$ constellatus es un comensal habitual del tracto gastrointestinal aunque puede producir infecciones en pacientes con factores de predisposición. La colecistostomía percutánea es el procedimiento de elección en pacientes no subsidiarios de intervención quirúrgica. En manos experimentadas, la colecistostomía percutánea es fácil de llevar a cabo, con bajo número de complicaciones y un porcentaje de éxito elevado.

\section{Bibliografía}

1. Strasberg SM. Clinical practice. Acute calculous cholecystitis. N Engl J Med 2008; 358: 2804.

2. Solomkin JS, Mazuski JE, Bradley JS, et al. Diagnosis and management of complicated intra-abdominal infection in adults and children: guidelines by the Surgical Infection Society and the Infectious Diseases Society of America. Clin Infect Dis 2010; 50: 133.

3. Claridge JE $3^{\circ}$, Attori S, Musher DM, Hebert J, Dunbar S. Streptococcus intermedius, $S$ constellatus and $S$ anginosus ("Strept milleri group") are of different clinical importante and are not equially associatd with abscess. Clin Infect Dis 2001; 32: 1511-5.

4. Bert F, Bariou-Lancelin M, Lambert-Zechovsky N. Clinical significance of bacteriemia involving the "Streptoccoccus milleri" group: 51 cases and review. Clin Infect Dis 1998; 27: 385.

5. Shinzato T, Saito A. A mechanism of pathogenicity of "Streptococcus milleri group" in pulmonary infections: synergy with an anaerobe. J Med Microbiol. 1994; 40: 118-23.

6. Cherng N, Witkowski ET, Sneider EB, et al. Use of cholecystostomy tubes in the management of patients with primary diagnosis of acute cholecystitis. J Am Coll Surg 2012; 214: 196

7. Byrne MF, Suhocki P, Mitchell RM, et al. Percutaneous cholecystostomy in patients with acute cholecystitis: experience of 45 patients at a US referral center. J Am Coll Surg 2003; 197: 206

8. R. Cortázar García, P. Sánchez Rodríguez y M. Ramos García. Colecistostomía percutánea como tratamiento de la colecistitis aguda en pacientes con alto riesgo quirúrgico. Radiología 2015. http://dx.doi.org/10.1016/j.rx.2015.09.006.

9. Morse BC, Smith JB, Lawdahl RB, Roettger RH. Management of acute cholecystitis in critically ill patients: contemporary role for cholecystostomy and subsequent cholecystectomy. Am Surg. 2010 Jul; 76 (7): 708-12. 